\title{
Influência da família na decisão profissional: opinião de adolescentes
}

\author{
Ricardo Ferreira Nepomuceno \\ Geraldina Porto Witter
}

\begin{abstract}
Resumo
Objetivou-se a influência familiar em adolescentes, comparando-os por gênero e escola pública e particular. Método: participaram 58 alunos de escola pública e particular de ambos os gêneros, com idades entre 16 e 19 anos. Utilizou-se questionário com 24 questões. Os resultados mostraram, na opinião dos participantes, atitude favorável das famílias na escolha da profissão e não foi forte a presença de crises familiares decorrentes da adolescência; forte e consistente influência da família, particularmente dos pais, sem imposição ou geração de problemas; o clima em termos de relações interpessoais nas famílias por tipos de escola e gênero tendeu a ser favorável a influências de seus membros nas escolhas dos adolescentes, bem como apoio em suas decisões envolvendo a profissão.
\end{abstract}

Palavras-chave: Trabalho, adolescência, escolha profissional.

\section{Influence of the family on the professional decision: adolescents' opinion}

\begin{abstract}
The aim of this study was to investigate the family's influence on the adolescents, taking into consideration their gender and whether they attended private or public schools. In order to develop the research we took fifty-eight students from public and private schools from both genders, their ages being between 16 and 19 years old. A questionnaire with 24 questions was used. The results revealed that the participants were favorable to the family's attitude concerning the choice of children's profession. The presence of conflict and familiar crises resulting from adolescence were not so strong. A strong and consistent influence of the family, particularly of the parents, without imposition, did not seem to cause problems. The atmosphere of interpersonal relations seemed to be good and favored the influence and support of the family regarding the adolescents's decisions about their profession.
\end{abstract}

Keywords: Labour, adolescence, occupational choice.

\section{La influencia de la familia en la decisión profesional: la opinión de adolescentes}

\section{Resumen}

El objetivo de este artículo fue abordar la influencia familiar en adolescentes, comparándolos por género y escuela pública y particular. Método: participaron 58 alumnos de escuela pública y particular de ambos géneros, con edades entre 16 e 19 años. Se utilizó un cuestionario con 24 preguntas. Los resultados mostraron, en la opinión de los participantes, actitud favorable de las familias en la elección de la profesión y no fue fuerte la presencia de crisis familiares en consecuencia de la adolescencia; fuerte y consistente influencia de la familia, particularmente de los padres, sin imposición o provocación de problemas; el clima cuanto a relaciones interpersonales en las familias por tipos de escuela y género tendió a ser favorable a influencias de sus miembros en las elecciones de los adolescentes, así como apoyo en sus decisiones envolviendo la profesión.

Palabras clave: Trabajo, adolescencia, escogimiento profesional. 


\section{Introdução}

A escolha da profissão é uma das decisões mais sérias da vida de uma pessoa, pois ela determina, de certo modo, o destino do indivíduo, bem como seu estilo de vida, a educação e até o tipo de pessoas com quem irá conviver no trabalho e na sociedade. Um erro de escolha equivale a um erro de vida (Gage, 2009). Com o aumento significativo dos processos industriais e intercâmbio comercial, a realidade da escolha profissional tornou-se mais complexa e assim também surgiu a necessidade de que os indivíduos fossem orientados quanto à sua escolha. Como lembraram Sales e cols. (2003), com a globalização e as múltiplas mudanças no mundo do trabalho, mais complexa ficou a tarefa de definir a escolha profissional. O quadro complica-se com o fato de as complexas e por vezes contraditórias competências exigidas serem muito variadas e progressivamente maiores, face aos vários contextos de trabalho, o que influi nas expectativas de quem está fazendo opções (Diedorff \& Morgeson, 2007), que se acresce o fato dos vários ambientes de trabalho oferecerem condições diferentes para ajustamento e socialização dos ingressantes (Bauer, Bodner, Erdogan, Truxillo, \& Tucker, 2007), tendendo a ser mais agressivas para mulheres (Miner-Rubino \& Cortina, 2007).

Devido à necessidade de identificar competências e minimizar acidentes de trabalho, surgiu a Psicologia Vocacional, acontecendo a expansão de seus programas no século $\mathrm{XX}$, paralelo ao contexto industrial, sendo que as novas exigências do ciclo profissional tornaram mais prementes as necessidades de orientação (Sales e cols., 2003; Meer, 2007).

Por conseguinte, partindo do ponto de vista da Orientação Profissional, como campo psicológico, emergiram várias posições teóricas, com diferentes atuações práticas, que, segundo Moura (2004, p. 19), podem ser agrupadas em três correntes teóricas principais: a psicodinâmica, a decisional e a desenvolvimental. Com relação a essas correntes teóricas, independente da linha assumida, parece, de acordo com essa mesma autora, "existir um consenso sobre a conceituação da Orientação Profissional". Além disso, enfoques teóricos diversos foram sendo elaborados e carecem de pesquisas (Primi \& Bueno, 2003). Decerto, isso é uma condição irrefutável para que os trabalhos desse campo de pesquisa sejam cada vez mais fidedignos e possivelmente toda essa expansão que vem acontecendo seja pela "insatisfação e consequente superação dos métodos psicométricos" (p.13), os quais precisam ser melhorados à luz de evidências científicas, havendo ainda a necessidade de criar novos instrumentos (Sheu \& Lent, 2007), especialmente em países com a variabilidade étnica e cultural como a existente no Brasil.

Atualmente, a orientação profissional é um tipo de intervenção pela qual o orientador minimiza fatores que dificultam a decisão profissional, tendo como objetivo fundamental e específico o de auxiliar o indivíduo no processo de escolha de modo que este realize opções ocupacionais adequadas (Ferretti, 1997). Dessa forma, quanto mais o indivíduo compreende e conhece as variáveis que podem influenciá-lo, mais controle terá sobre suas escolhas. Sabe-se que cada vez mais pessoas procuram esse tipo de orientação e, devido a essa crescente demanda, foi necessário o desenvolvimento de instrumentos adequados para lidar com a complexidade e a escassez de trabalhos sistematizados que se propusessem a investigar o dilema da orientação profissional de forma elaborada.

Inegavelmente as chances de êxito na escolha de uma carreira aumentam à medida que há aprimoramentos muito mais aprofundados em recursos e técnicas. Porém deve-se levar em conta uma variável relevante para a escolha, no que diz respeito ao gênero. Por exemplo, a educação é no Brasil um cenário de trabalho predominantemente feminino, mas os cargos de maior poder estão, via de regra, nas mãos masculinas. Deve-se considerar esse fator, pois as profissões ditas femininas são também as que tendem a ter menores salários e menos prestígio (Dália, 1983; Silva, 1996).

Existem vários outros fatores que são determinantes na escolha profissional e que certamente têm influência do sistema político e social vigente (Soares, 2002). Para melhor entender esses fatores, realizou-se uma divisão para fins puramente didáticos (visto que na realidade sempre atuam juntos) em fatores políticos, econômicos, sociais, educacionais, psicológicos e familiares. O fator político refere-se às políticas governamentais em relação à educação, principalmente ao ensino médio, pós-médio, profissionalizante e universitário; os fatores econômicos, por sua vez, dizem respeito à globalização, informação das profissões, falta de oportunidades, desemprego, falta de planejamento econômico e todas as implicabilidades do sistema no qual as pessoas se inserem; os fatores sociais dizem respeito à divisão da sociedade em classes sociais, busca da promoção social por meio do estudo (curso médio e superior), influência da sociedade na família e os efeitos da globalização na cultura e na família; os fatores educacionais compreendem, de forma geral, todo o sistema de ensino brasileiro, como a falta de investimentos no setor e a questão da universidade pública e privada no país; finalmente, os fatores familiares impõem uma parte importante no processo de impregnação da ideologia vigente. $A$ busca de realização das expectativas familiares em detrimento dos interesses pessoais influencia na decisão e na fabricação dos diferentes papéis profissionais (Soares, 2002), bem como pelos modelos que apresenta.

Skinner (1977), Pires e Araújo, (1976), entre outros, defendem que as escolhas não são dadas como opção, pois são dependentes de alguns eventos diversos que exercem influência sobre o comportamento e suas ações e Bohoslavsky (1980) fala em especial que as escolhas profissionais estão multi e sobredeterminadas pela família.

Silva (1996) diz também que a escolha profissional do jovem reativa as escolhas dos pais, acarretando, assim, antigos conflitos que muitas vezes não foram superados. Ademais, esse momento também pode ser encarado pelos pais como uma possibilidade de reparação das próprias escoIhas. Isso sugere que o jovem seja o depositário de fantasias inconscientes da família e, dessa maneira, cabe-lhe realizar aquilo que a família não realizou ou mesmo dar continuidade a tarefas já desenvolvidas por eles. A família é a célula que 
faz intermediação entre o social e o indivíduo e também é responsável pelos valores morais e pela cultura. O jovem é, em parte, o resultado da relação da família com a sociedade.

$\mathrm{O}$ adolescente vem sendo foco de muitas pesquisas na área, principalmente pelas várias dificuldades sociais e familiares que surgem nessa fase, sendo vista inclusive como fase de rebelião, muitas vezes prevalece um modelo de um antiadulto desafiador, cercado por atitudes de desobediência (Lemos, 2001). Ligados diretamente à natureza do jovem, esses desequilíbrios em estabilidade pressupõem uma crise preexistente no adolescente (Bock, 2001), até mesmo porque o adolescente que é considerado normal também tem problemas (Rosas, 1980) e fazer uma opção neste momento pode tornar-se uma tarefa difícil.

Outros fatores como mercado de trabalho, importância social, remuneração, tipo de trabalho (braçal/intelectual) e as habilidades necessárias para o seu desempenho exercem, sem dúvida, grande influência na hora da escolha, porém, sem o risco de exageros, determinante decisivo dessa escoIha não é biológico (vocação) e sim de natureza econômica e social, ligado diretamente às oportunidades de escolarização do indivíduo (Bock, Furtado, \& Teixeira, 1991), que Ihe darão as condições básicas de escolaridade (Lara Campos, 2006).

Talvez a principal dificuldade ainda seja desfazer mitos e elucidar o conhecimento de profissões, carreiras, cursos de nível técnico e superior, vestibulares e mercado de trabalho, com informações concretas e atualizadas. Conforme Rosas (1980), há uma ignorância generalizada e muito do que se diz a respeito é distorcido ou até mesmo fruto de experiências pessoais, que não podem, portanto, ser generalizadas.

Assim, há necessidade de pesquisar muitos aspectos envolvendo a orientação profissional. Dentre eles, é preciso conhecer as variáveis familiares que influem nos jovens segundo a opinião dos mesmos.

Considerando o contexto aqui mencionado, foram estabelecidos os seguintes objetivos para a pesquisa: (a) detectar variáveis relevantes na escolha profissional com ênfase nas originárias da família; (b) verificar como as referidas variáveis atuam no que concerne a alunos matriculados em escola pública e escola particular e (c) verificar a atuação das mesmas variáveis nos dois gêneros.

\section{Método}

\section{Participantes}

Participaram da pesquisa 58 alunos de segundo e terceiro ano do ensino médio com idades acima de 16 anos, sendo 25 de escola pública (11 do sexo masculino e 14 do feminino) e 33 de escola particular (20 do sexo masculino e 13 do feminino). Todos os alunos da escola pública estavam cursando o $3^{\circ}$ ano do ensino médio e, na escola particular, 13 participantes do gênero masculino estavam no $3^{\circ}$ ano do ensino médio e 7 estavam no segundo. No gênero feminino, 8 alunas estavam no terceiro ano e 5 estavam no segundo. A média de idade do gênero masculino da escola pública foi de 18,09 e do feminino foi 17,31 . Na escola particular, a média de idade masculina foi 17,15 anos e feminina, 7,3 . Todos os participantes da escola particular eram solteiros e, na escola pública, havia somente uma participante casada. No que diz respeito ao trabalho, na escola pública três participantes masculinos trabalhavam e, entre as moças, cinco tinham emprego. Na escola particular, cinco rapazes e cinco moças trabalhavam.

Quanto à média de idade dos pais, verificou-se 51,8 anos para os pais dos jovens e 47,33 para as mães das jovens de escola pública; na escola particular, foi, respectivamente, de 46,16 e 45,75. O nível de escolaridade dos pais dos alunos da escola pública variou de analfabeto ao ensino médio e, das alunas, foi de analfabeto ao ensino superior. $\mathrm{Na}$ escola particular, os pais dos garotos e garotas tiveram educação variando do ensino fundamental ao superior. Em relação à profissão, houve grande variação para os pais, mas as mães estavam mais voltadas para o trabalho doméstico ou que não exigia formação sofisticada. A renda familiar dos pais de escola particular ficou entre $R \$ 301,00$ e $R \$ 1.000,00$ e, na particular, foi superior a $\mathrm{R} \$ 1.500,00$.

\section{Material}

Termos de Consentimento Livre e Esclarecido (TCLE) - foram usados três: um assinado pelo diretor, outro pelos pais dos adolescentes e o último pelos adolescentes.

Questionário específico - constituído de 24 perguntas do tipo semiaberto, abrangendo dados para a caracterização do sujeito, suas condições de vida e questões específicas sobre como viram a participação dos familiares no processo e motivação da escolha profissional. Esse questionário teve como fonte de apoio a dissertação de mestrado de Veloso (1981), com algumas adaptações.

\section{Procedimento}

Após o consentimento do Comitê de Ética da UMC (Processo $n^{\circ}$ 018/2005 CAAE-0006.0.2373000-05), foram assinados os termos de Consentimento Livre e Esclarecido pelo diretor da escola, pelos pais dos adolescentes e pelos próprios adolescentes. O questionário foi aplicado de forma coletiva, na própria sala de aula, em horários e dias que foram convenientes para a escola. A aplicação foi feita pelo pesquisador alertando os participantes que, conforme constava no TCLE, seriam respostas absolutamente confidenciais e não influiriam em sua vida acadêmica. Não foi estipulado tempo para a resposta.

\section{Resultados e discussão}

A primeira pergunta feita aos alunos com o objetivo de obter resultados foi "Como é o relacionamento com sua família?". Dessa forma, foi feita a análise de dados categorizando as respostas fornecidas pelos participantes. 
Tabela 1. Relacionamento com a família na opinião dos adolescentes.

\begin{tabular}{|c|c|c|c|c|c|c|c|c|c|c|c|c|c|c|}
\hline \multirow{2}{*}{ Categorias } & \multicolumn{2}{|c|}{$\mathrm{Pu} \mathrm{M}$} & \multicolumn{2}{|c|}{$\mathrm{Pa} \mathrm{M}$} & \multicolumn{2}{|c|}{ Total M } & \multicolumn{2}{|c|}{$\mathrm{PuF}$} & \multicolumn{2}{|c|}{$\mathrm{Pa} \mathrm{F}$} & \multicolumn{2}{|c|}{ Total F } & \multicolumn{2}{|c|}{ Total Geral } \\
\hline & $\mathrm{F}$ & $\%$ & $F$ & $\%$ & $F$ & $\%$ & $F$ & $\%$ & $F$ & $\%$ & $F$ & $\%$ & $\mathrm{~F}$ & $\%$ \\
\hline Bom & 4 & 50 & 11 & 55 & 15 & 53,5 & 6 & 60 & 7 & 53,8 & 13 & 56,5 & 28 & 54,9 \\
\hline Ótimo & 2 & 25 & 5 & 25 & 7 & 25 & 0 & 0 & 5 & 38,5 & 5 & 21,7 & 12 & 23,5 \\
\hline Regular & 2 & 25 & 2 & 10 & 4 & 14,3 & 2 & 20 & 1 & 7,7 & 3 & 13 & 7 & 13,7 \\
\hline Ruim & 0 & 0 & 1 & 5 & 1 & 3,6 & 2 & 20 & 0 & 0 & 2 & 8,7 & 3 & 5,9 \\
\hline Péssimo & 0 & 0 & 1 & 5 & 1 & 3,6 & 0 & 0 & 0 & 0 & 0 & 0 & 1 & 2 \\
\hline Total & 8 & 100 & 20 & 100 & 28 & 100 & 10 & 100 & 13 & 100 & 23 & 99,9 & 51 & 100 \\
\hline
\end{tabular}

Fonte: Elaborado pelos autores.

Tabela 2. Membro da família com quem os adolescentes informaram se relacionar melhor.

\begin{tabular}{|c|c|c|c|c|c|c|c|c|c|c|c|c|c|c|}
\hline \multirow{2}{*}{ Itens } & \multicolumn{2}{|c|}{$\mathrm{Pu} \mathrm{M}$} & \multicolumn{2}{|c|}{$\mathrm{Pa} \mathrm{M}$} & \multicolumn{2}{|c|}{ Total M } & \multicolumn{2}{|c|}{$\mathrm{PuF}$} & \multicolumn{2}{|c|}{$\mathrm{PaF}$} & \multicolumn{2}{|c|}{ Total F } & \multicolumn{2}{|c|}{ Total Geral } \\
\hline & $F$ & $\%$ & $\mathrm{~F}$ & $\%$ & $\mathrm{~F}$ & $\%$ & $\mathrm{~F}$ & $\%$ & $F$ & $\%$ & $\mathrm{~F}$ & $\%$ & $\mathrm{~F}$ & $\%$ \\
\hline Pais & 12 & 60 & 8 & 80 & 20 & 66,6 & 9 & 81,8 & 9 & 60 & 18 & 69,2 & 38 & 67,8 \\
\hline Irmãos & 3 & 15 & 2 & 20 & 5 & 16,7 & 1 & 9,1 & 5 & 33,3 & 6 & 23,1 & 11 & 19,5 \\
\hline Outros Parentes & 5 & 25 & 0 & 0 & 5 & 16,7 & 1 & 9,1 & 1 & 6,7 & 2 & 7,7 & 7 & 12,5 \\
\hline Total & 20 & 100 & 10 & 100 & 30 & 100 & 11 & 100 & 15 & 100 & 26 & 100 & 56 & 99,8 \\
\hline
\end{tabular}

Fonte: Elaborado pelos autores.

Consoante com o expresso na Tabela 1, na opinião dos participantes, a tendência em todos os grupos foi considerar que se relacionam bem com a família, tendendo as respostas a se concentrarem em Bom e Ótimo. A melhor avaliação ocorreu no grupo PuF com $60 \%$ de Bom e entre as alunas da escola particular que, entre Bom (53,8\%)e Ótimo (38,5\%), ficou com 92,3 de manifestações positivas. Foi igualmente positiva a avaliação por gênero, sendo vista como Ótima por $25 \%$ do gênero masculino e por $22 \%$ do feminino e como Boa por $53,6 \%$ deles e $56,5 \%$ delas. Conseqüentemente, o total reflete esta percepção positiva no relacionamento com a família (Bom = 55\%; Ótimo = 23,5\%).

Para verificar se havia concordância na opinião dos participantes tendo em vista a variável gênero, foi feito o teste de correlação de postos (Siegel, 1956) para $\mathrm{N}=5, \mathrm{p} \leq$ 0,05 e $\mathrm{r}_{0}=0,75$. Foi obtido 0,98 , podendo-se afirmar que os dois grupos consideram igualmente boas as relações com seus familiares. Na comparação entre estudantes de escola pública e particular, a correlação foi também 0,98 , ou seja, é opinião estatisticamente equivalente que ambos os grupos consideram positivas suas relações familiares.

Tendo em vista a comparação de avaliação positiva (Bom + Excelente) e negativa (Regular + Ruim +Péssimo), foram somadas as parcelas dos totais e feito o $\chi^{2}$ para n.g.l $=2, \chi^{2}=5,99$, mantendo-se o n.sig adotado para o estudo em $p \leq 0,5$. O valor obtido foi 18,00 , o que permite assegurar que os participantes no total da amostra consideraram bom o relacionamento familiar. Estes resultados permitem esperar uma atitude favorável das famílias na escolha da profissão por seus filhos e não marcam a presença forte de crises familiares (Bock, 2001), mas similaridade com os dados de Veloso (1981), em que também não houve indício de sentirem pressão familiar.

Os dados expressos na Tabela 2 elucidam que houve uma concordância geral dos participantes no que diz respeito ao membro da família com quem melhor se relacionam, tendendo a maioria das respostas para a categoria Pais. A maior frequência foi no grupo da Escola Pública de gênero feminino, com $89,1 \%$, seguido pelos participantes da escola particular de gênero masculino (80\%). Os demais grupos obtiveram $60 \%$ das respostas neste quesito. Além disso, a correlação obtida foi de 0,88 , sendo $r_{0}=0,87$, assim, pode-se dizer que há similaridade entre ambos os gêneros. Na comparação entre os participantes de escola pública e particular, foi observado $r_{0}=0,50$ e $r_{c}=0,87$, sendo possível, dessa forma, afirmar que não houve similaridade entre os dois tipos de escolas quanto à pessoa da família com quem melhor se relacionam.

Comparando-se também as categorias pais e outros parentes (Irmãos + Outros Parentes), foram somadas as parcelas dos totais dessas duas categorias e usado o $\chi^{2}$ para n.g.l. $=1, \chi_{c}^{2}=3,86, p \leq 0,05$. O resultado observado foi 7,14 e, assim sendo, pode-se afirmar que a avaliação final indica que realmente são com os pais os relacionamentos mais valorizados pelos participantes na escolha profissional. 
Tabela 3. Interferência da família nas decisões de escolha profissional.

\begin{tabular}{|c|c|c|c|c|c|c|c|c|c|c|c|c|c|c|}
\hline \multirow{2}{*}{ Categorias } & \multicolumn{2}{|c|}{ Pu M } & \multicolumn{2}{|c|}{$\mathrm{Pa} \mathrm{M}$} & \multicolumn{2}{|c|}{ Total M } & \multicolumn{2}{|c|}{$\mathrm{PuF}$} & \multicolumn{2}{|c|}{$\mathrm{Pa} F$} & \multicolumn{2}{|c|}{ Total F } & \multicolumn{2}{|c|}{ Total Geral } \\
\hline & $F$ & $\%$ & $F$ & $\%$ & $F$ & $\%$ & $\mathrm{~F}$ & $\%$ & $F$ & $\%$ & $\mathrm{~F}$ & $\%$ & $F$ & $\%$ \\
\hline $\begin{array}{l}\text { Sim } \\
\text { Não }\end{array}$ & $\begin{array}{l}2 \\
3\end{array}$ & $\begin{array}{l}18,2 \\
27,3\end{array}$ & $\begin{array}{l}6 \\
6\end{array}$ & $\begin{array}{l}30 \\
30\end{array}$ & $\begin{array}{l}8 \\
9\end{array}$ & $\begin{array}{c}25,8 \\
29\end{array}$ & $\begin{array}{l}3 \\
6\end{array}$ & $\begin{array}{l}23,1 \\
46,1\end{array}$ & $\begin{array}{l}1 \\
3\end{array}$ & $\begin{array}{c}7,7 \\
23,1\end{array}$ & $\begin{array}{l}4 \\
9\end{array}$ & $\begin{array}{l}15,4 \\
34,6\end{array}$ & $\begin{array}{l}12 \\
18\end{array}$ & $\begin{array}{c}21 \\
31,6\end{array}$ \\
\hline Mais ou menos & 6 & 54,5 & 8 & 40 & 14 & 45,2 & 4 & 30,8 & 9 & 69,2 & 13 & 50 & 27 & 47,4 \\
\hline Total & 11 & 100 & 20 & 100 & 31 & 100 & 13 & 100 & 13 & 100 & 26 & 100 & 57 & 100 \\
\hline
\end{tabular}

Fonte: Elaborado pelos autores.

Tabela 4. Áreas de interferência da família segundo os adolescentes.

\begin{tabular}{|c|c|c|c|c|c|c|c|c|c|c|c|c|c|c|}
\hline \multirow{2}{*}{ Categorias } & \multicolumn{2}{|c|}{$\mathrm{PuM}$} & \multicolumn{2}{|c|}{$\mathrm{Pa} \mathrm{M}$} & \multicolumn{2}{|c|}{ Total M } & \multicolumn{2}{|c|}{$\mathrm{PuF}$} & \multicolumn{2}{|c|}{$\mathrm{PaF}$} & \multicolumn{2}{|c|}{ Total F } & \multicolumn{2}{|c|}{ Total Geral } \\
\hline & $\mathrm{F}$ & $\%$ & $\mathrm{~F}$ & $\%$ & $\mathrm{~F}$ & $\%$ & $\mathrm{~F}$ & $\%$ & $\mathrm{~F}$ & $\%$ & $\mathrm{~F}$ & $\%$ & $\mathrm{~F}$ & $\%$ \\
\hline Estudo & 5 & 21,7 & 4 & 16,7 & 9 & 19,1 & 7 & 31,8 & 4 & 22,2 & 11 & 27,5 & 20 & 23 \\
\hline Profissão & 5 & 21,7 & 5 & 20,8 & 10 & 21,3 & 4 & 18,2 & 4 & 22,2 & 8 & 20 & 18 & 20,7 \\
\hline Namoro & 5 & 21,7 & 4 & 16,7 & 9 & 19,1 & 5 & 22,7 & 4 & 22,2 & 9 & 22,5 & 18 & 20,7 \\
\hline Religião & 4 & 17,4 & 4 & 16,7 & 8 & 17 & 3 & 13,6 & 1 & 5,5 & 4 & 10 & 12 & 13,8 \\
\hline Amigos & 4 & 17,4 & 7 & 29,1 & 11 & 23,4 & 3 & 13,6 & 1 & 5,5 & 4 & 10 & 15 & 17,2 \\
\hline Outros & 0 & 0 & 0 & 0 & 0 & 0 & 0 & 0 & 4 & 22,2 & 4 & 10 & 4 & 4,6 \\
\hline Total & 23 & 99,9 & 24 & 100 & 47 & 99,9 & 22 & 99,9 & 18 & 99,8 & 40 & 100 & 87 & 100 \\
\hline
\end{tabular}

Fonte: Elaborado pelos autores.

A categoria mais frequente no que diz respeito à interferência da família nas decisões dos participantes (Tabela 3) foi Mais ou Menos, com um total de $47 \%$ de todas as respostas. Notou-se ainda que, no grupo do gênero feminino da escola particular, foi onde houve a maior frequência nesta categoria, com $69,2 \%$ das respostas. Em contrapartida, os participantes femininos da escola pública somaram o menor resultado, com $30,8 \%$ das respostas. A categoria Sim foi a que obteve menor frequência das respostas, com $21 \%$ do total geral de respostas. A correlação quanto à concordância na opinião dos participantes para $\left(N=3, p \leq 0,05\right.$ e $\left.r_{c}=0,87\right)$, foi $r_{0}=1$, podendo-se afirmar, então, que entre os gêneros houve semelhança referente à interferência da família nas decisões dos participantes. Quanto à confrontação dos dados dos estudantes de escola pública e particular, a correlação foi a mesma da comparação anterior. Comparando-se as três categorias da Tabela 3 , foi utilizado o teste de $\chi^{2}$, para n.g.l. = $2, \chi_{c}^{2}=5,99$ e $p \leq 0,05$.. O resultado apurado foi 5,98, H0 não foi rejeitada, não há diferença significante, podendo-se então afirmar que a avaliação total da amostra indica similaridade entre as respostas.

A Tabela 4 mostra os principais tipos de interferência da família nas decisões dos participantes da pesquisa. As categorias mais presentes nos resultados gerais foram Estudo, com $23 \%$, e Profissão e Namoro, com $20,7 \%$ cada uma.
Amigos e Religião obtiveram um percentual aproximado, com $17,2 \%$ e $13,8 \%$ respectivamente. A maior porcentagem observada foi na escola particular, entre os participantes de gênero masculino (29,2\%). A correlação mostrou que as respostas dadas pelos alunos da escola particular dos tipos de interferência da família não são semelhantes às respostas fornecidas pelos alunos da escola pública, pois a correlação foi de $0,44\left(r_{c}=0,70\right)$. O mesmo ocorreu em relação à comparação de respostas dos participantes do gênero masculino e feminino: a correlação entre as respostas fornecidas pelos participantes foi de $r_{0}=0,68$, ou seja, não significante. Embora com variações, é em Estudo, Namoro e Escolha Profissional que mais consideraram ter interferência familiar.

Por meio do teste de Qui-quadrado, constatou-se, dentre as categorias do total geral, com exceção da categoria Outros, que não se obteve frequência significativa nos seguintes resultados: $\chi_{0}^{2}=2,33$, e $\chi_{c}^{2}=9,49$, para n.g.l $=4$. Com esses resultados, é possível afirmar que não houve diferença no que diz respeito à interferência da família nos vários segmentos de decisões.

Um dos itens do questionário pedia aos participantes que avaliassem a influência motivadora de vários personagens nas suas possíveis escolhas profissionais. Os resultados aparecem nas Figuras 1 e 2. 


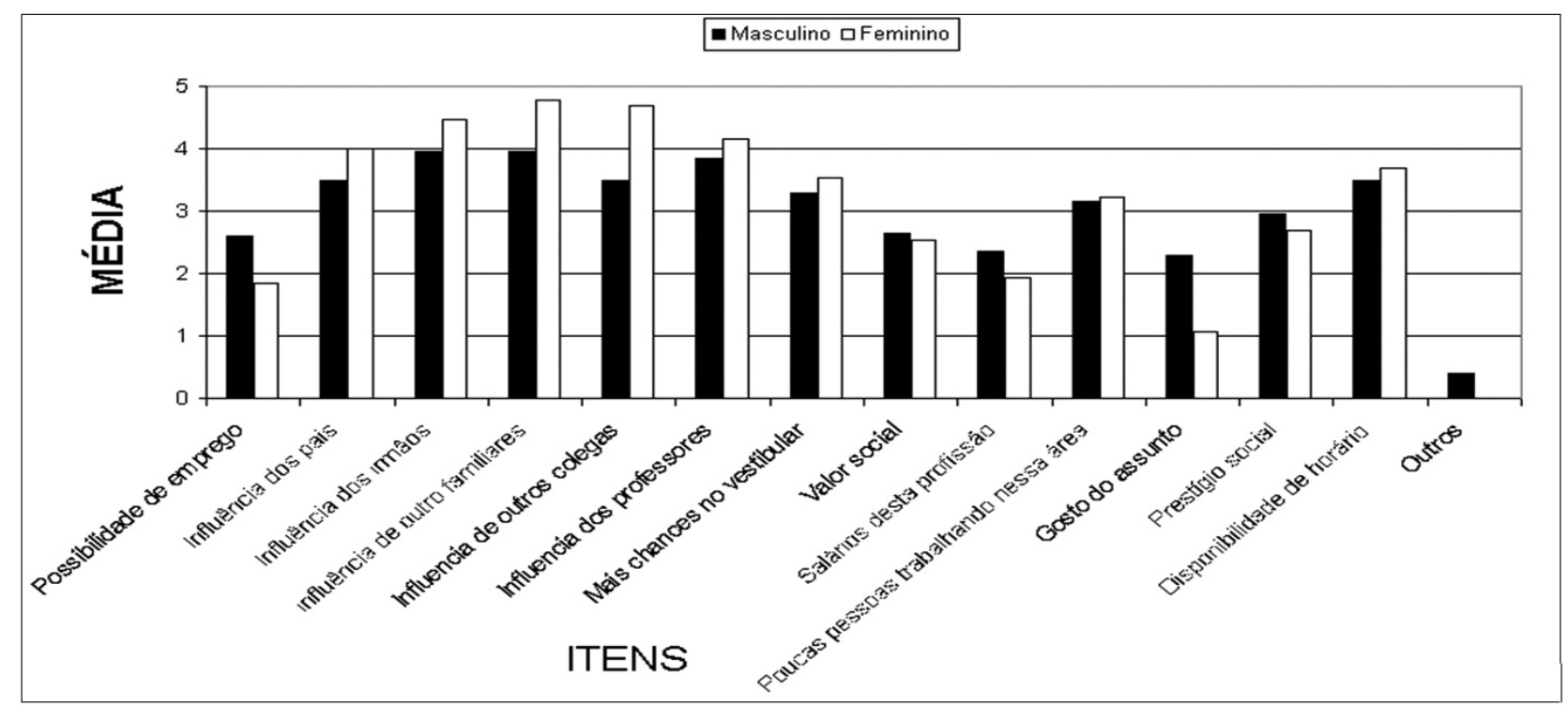

Figura 1. Motivação para a escolha profissional: escola particular

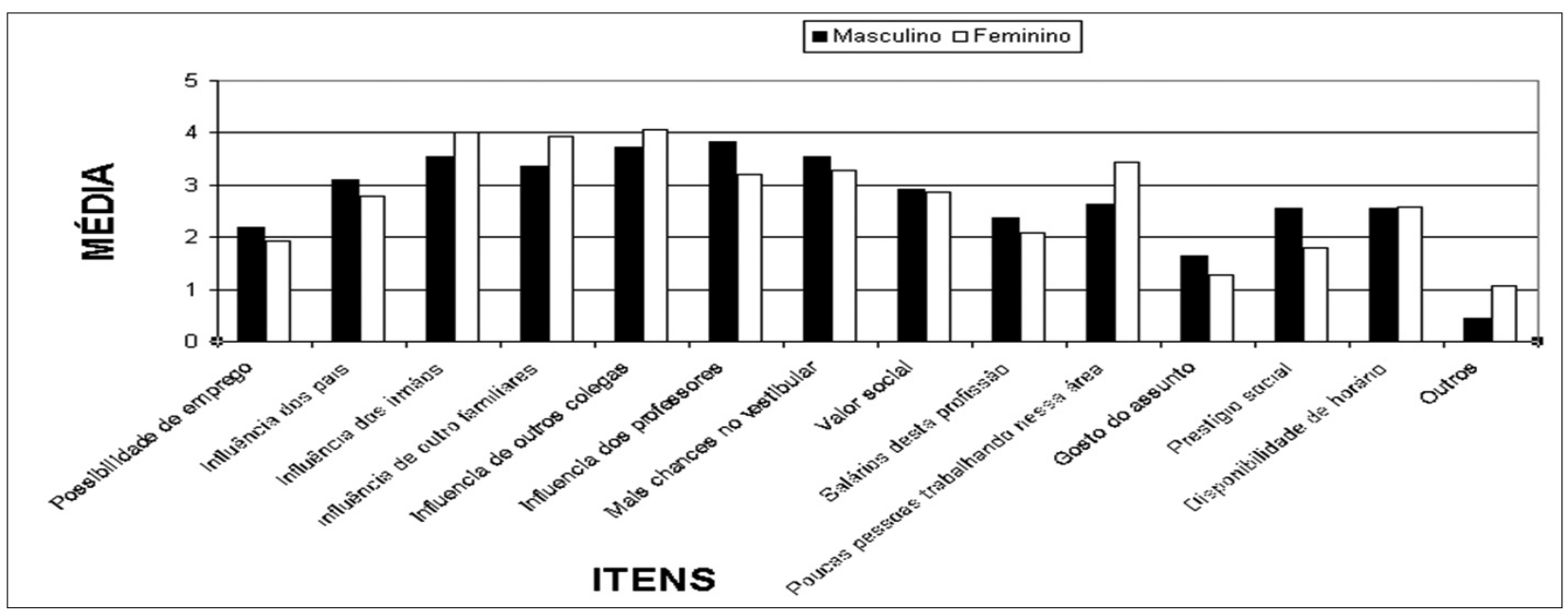

Figura 2. Motivação para a escolha profissional: escola pública

Através dos resultados expressos na Figura 1, podese observar que, no que diz respeito à escola particular no gênero masculino, os itens de maior motivação para a escolha profissional foram influência dos irmãos e de outros familiares, ambos com média de 3,95, e influência dos professores, com 3,85 . Verificou-se que houve correlação entre as respostas dadas entre os alunos do gênero masculino e feminino $\left(r_{0}=0,97\right.$ e $\left.r_{c}=0,75\right)$. Pode-se dizer que a influência da família é mais forte, mas também há influência do ambiente acadêmico.

Os dados da Figura 2 apontam que as principais fontes de motivação na escola pública, entre os participantes masculinos, foram influência dos professores, com uma média de 3,82 , influência de outros colegas, com 3,73 , e os itens influência dos irmãos e mais chances no vestibular, ambos com a média de 3,55 . No caso feminino, os resultados foram: influência de outros colegas, com média de 4,07, influência dos irmãos, com 4,0, e influência de outros familiares, que obteve a média de 3,93. De um modo geral, há na escola pública impacto maior do meio acadêmico, mas também é apreciável a influência familiar.

Embora a influência familiar se faça presente, não foram detectados sinais de fortes conflitos familiares, nem interferência abusiva da família (Bohoslavski, 1980). Certamente há a necessidade de mais pesquisas comparando adolescentes de níveis socioeconômicos distintos já que podem ter estilos parentais diferentes, inclusive nas escolhas profissionais dos filhos (Santos, 2003), o que pede um cruzamento das variáveis em tela. Também se concorda com Sparta, Bardagi e Nachtigall (2003), os quais afirmam que só o tipo de escola parece insuficiente para classificar os sujei- 
tos por nível socioeconômico, com o que se teve o cuidado de usar apenas tipo de escola. Outros indicadores precisam ser usados concomitantemente.

Com a aplicação da correlação de Spearman, verificouse que existe correlação entre os gêneros masculino e feminino $\left(r^{2} 0=0,86\right.$ e $\left.r^{2} c=0,49\right)$. Também foram comparadas por meio do mesmo teste as respostas dos participantes de gênero masculino dos dois tipos de escola pesquisados e foi observado que existe correlação, uma vez que $r^{2} 0=0,84$. Na equiparação das respostas dos participantes de gênero feminino das duas escolas, verificou-se $r^{2} 0=0,86$, sendo assim, existe correlação. Os dados sugerem a necessidade de aprofundar os estudos sobre a influência da família na escolha profissional e no próprio trabalho (Casper, Eby, Bordeauz, \& Lockwood, 2007; Steenbergen, Ellemers, \& Mooijaart, 2007), o que raramente tem ocorrido no Brasil. Entretanto, um clima familiar favorável como o aqui registrado é um facilitador a ser considerado no processo de orientação profissional e de carreira.

De um modo geral, os dados obtidos diferem das projeções decorrentes do enfoque psicanalítico (Barreto \& AielloVaisberg, 2007). Os participantes da presente pesquisa mostraram confiança e credibilidade em relação ao apoio familiar e ausência de drama na escolha da profissão, estando consoantes com condições estimuladoras positivas no lar, mais comum em outros enfoques (Moura, 2004; Lara Campos, 2006).

Certamente a complexidade da orientação vocacional e profissional também requer uma formação mais ampla e ao mesmo tempo mais profunda, a qual está a merecer pesquisas no Brasil como, por exemplo, a realizada por Mulcahy (2007) na Austrália. Também é preciso estar ciente de que o trabalho deve incluir a transição da educação vocacional para o trabalho (Brekke, 2007). Mas, ainda, para bem servir ao orientando e prestar um serviço relevante à sociedade ,é necessário investir na formação que privilegie a pesquisa (Li-zhong, 2007).

\section{Conclusões}

Os resultados obtidos confirmam a complexidade de variáveis que influem na escolha profissional, o que requer uma orientação adequada para o adolescente, como lembram Primi e Bueno (2003). Para tanto, é imprescindível uma formação adequada para os que pretendem trabalhar na área, o que influi certamente uma sólida base científica, conhecimento dos referenciais técnicos específicos, dos instrumentos de avaliação e dos procedimentos confiáveis de orientação, possivelmente mais produtiva segundo o enfoque comportamental (Bardagi \& Sparta, 2003).

Por meio dos resultados, na opinião dos participantes, as principais fontes de influência na decisão profissional, na amostra, foram família, colegas, outros familiares, irmãos e professores. O clima existente em termos de relações interpessoais na família dos dois tipos de escola e para os dois gêneros tendeu a ser favorável a influências de seus membros nas escolhas dos adolescentes, bem como um possível apoio em suas decisões envolvendo a profissão. Entretanto, entre estudantes femininos da escola pública, essa influência é me- nos notável. As relações interpessoais positivas com colegas e professores também viabilizam influências deles nas opções profissionais dos adolescentes, sendo de se destacar que, na escola pública, o impacto sobre as meninas foi mais forte.

Em síntese, no que diz respeito à influência na escolha profissional, pode-se concluir, nos grupos estudados, que a família dos alunos da escola particular interfere pouco mais do que a família da escola pública, em se tratando do gênero feminino, e no gênero masculino não houve diferença estatística.

A opinião dos adolescentes oferece pistas relevantes para o planejamento de programas de orientação incluindo membros da família. Os resultados mostram que há muitos aspectos a pesquisar, inclusive que permitam desenvolver instrumentos psicometricamente mais seguros do que o questionário.

\section{Referências}

Bardagi, M. R., \& Sparta, M. (2003). Atualização e instrumentos na área de Orientação Profissional. Anais do Congresso Nacional de Psicologia Escolar e Educacional, 6 (pp. 451-460). Salvador: Faculdade Ruy Barbosa.

Barreto, M. A., \& Aiello-Vaisberg, T. (2007). Escolha profissional e dramática do viver adolescente. Psicologia \& Sociedade, 19(1), 107-114.

Bauer, T. N., Bodner, T., Erdogan, B., Truxillo, D. M., \& Tucker, J. S. (2007). Newcomer adjustment during organizational socialization: a meta-analytic review of antecedents, outcomes and methods. Journal of Applied Psychology, 92(3), 707-721.

Bock, A. M. B., Furtado, O., \& Teixeira, M. de L. T. (1991). Psicologias. São Paulo: Saraiva.

Bock, A. M. B. (2001). Psicologia sócio-histórica. São Paulo: Cortez.

Bohoslavsky, R. (1980). Orientação vocacional: a estratégia clínica (3a ed.). São Paulo: Martins Fontes.

Brekke, I. (2007). Ethnic background and the transition from Vocational Education to Work: a multi-level analysis of differences in labor market outcomes. Journal of Education and work, 20(3), 229-254.

Casper, W. J., Eby, L. T., Bordeaux, C., \& Lockwood, A. (2007). A review of research methods in 10/OB Work-Family research. Journal of Applied Psychology, 92(1), 28-43.

Dália, E. da C. P. (1983). Mulher, Educação e Trabalho. Dissertação de Mestrado, Universidade Federal da Paraíba, João Pessoa.

Diedorff, E. C., \& Morgeson, F. P. (2007). Consensus in work role requirements: the influence of discrete occupational context on role expectations. Journal of Applied Psychology, 92(5), 1228-1241.

Ferretti, C. J. (1997). Uma nova proposta de Orientação Profissional. São Paulo: Cortez. 
Gage, N. L. (2009). A conception of teaching. New York, NY.: Springer.

Lara Campos, K. C. de. (2006). Construção de uma escala de empregabilidade: competências e habilidades pessoais. Tese de doutorado, Instituto de Psicologia, Universidade de São Paulo, São Paulo.

Lemos, C. G. de. (2001). Adolescência, identidade e escolha da profissão no mundo do trabalho atual. São Paulo: Vetor.

Li-zhong, O. (2007). A historic choice: the Ninglo Module of Vocational Higher Education for serving the community and society. US_China Education Review, 4(1), 20-24.

Meer, J. (2007). Evidence on the returns to Secondary Vocational Education. Economics of Education Review, 26(5), 559-573.

Miner-Rubino, K., \& Cortina, L. M. (2007). Beyond targets: consequences of vicarious exposure to misogyny at work. Journal of Applied Psychology, 92(5), 1254-1269.

Moura, C. B. (2004). Orientação Profissional sob o enfoque da análise do comportamento. São Paulo: Alínea.

Mulcahy, D. (2007). Managing spaces: (Re) working relations of strategy and spatiality in vacational education and tranining. Studies in Continuing Education, 29(2), 143-162.

Pires, J., \& Araújo, G. B. de. (1976). Orientação profissional. Natal: Editora Universitária.

Primi, R., \&Bueno, J.M. H. (2003). Escalaparaavaliação do desempenho de alunos de psicologia no estágio em psicodiagnóstico. Anais do Congresso Nacional de Psicologia Escolar e Educacional, 6 (p. 27). Salvador: Faculdade Ruy Barbosa.

Rosas, P. (1980). Vocação e profissão (3a ed.). Petrópolis, RJ: Vozes.

Sales, J. L. L., Souza. R. da S., Santos, E. C., Cerqueira, I. R. G., Oliveira, C. M., Nascimento, E. de S. (2003). Orientação

\section{Sobre os autores}

Ricardo Ferreira Nepomuceno (ricardofnb@yahoo.com.br)

Universidade de Mogi das Cruzes, Mogi das Cruzes - SP

Geraldina Porto Witter (gwitter@uol.com.br)

Universidade Camilo Castelo Branco, São Paulo - SP
Vocacional: o desafio dos novos campos de atuação. Anais do Congresso Nacional de Psicologia Escolar e Educacional, 6 (pp. 460-461). Salvador: Faculdade Ruy Barbosa.

Santos, C. R. G. dos. (2003). Estresse e estudos Parentais. Dissertação de Mestrado, Pontifícia Universidade Católica de Campinas, Campinas, São Paulo.

Sheu, H. B., \& Lent, R. W. (2007). Development and initial validation of the multicultural counseling self-efficacy scale-racial diversity form. Psychotherapy, theory, research, practice, training, 44(1), 30-45.

Siegel, S. (1956). Nonparametric statistics for the behavioral sciences. New York: McGraw-Hill Book.

Silva, L. B. de C. (1996). A escolha da profissão: uma abordagem psicossocial. São Paulo: Unimarco.

Skinner, B. F. (1977). O Mito da Liberdade (3a ed.) (M. L. F. Goulart, Trad.). Rio de Janeiro: Edições Bloch.

Soares, D. H. P. (2002). A escolha profissional do jovem ao adulto. São Paulo: Sumus.

Sparta, M., Bardagi, M. P., \& Nachtigall, V. B. (2003). Análise das diferenças de gênero e nível sócio-econômico nas escolhas profissionais de adolescentes. Anais do Congresso Nacional de Psicologia Escolar e Educacional, 6 (p. 462-423). Salvador: Faculdade Ruy Barbosa.

Steenbergen, E. F. van, Ellemers, N., \& Mooijaart, A. (2007). How work and family can facilitate each other: distinct types of workfamily facilitation and outcomes for women and men. Journal of Occupational Health Psychology, 12(3), 279-300.

Veloso, C. A. da N. (1981). Influências sócio-culturais na escolha do curso universitário por parte da clientela oriunda do curso formal e do supletivo. Dissertação de Mestrado, Universidade Federal da Paraíba, João Pessoa.

\section{Correspondência}

Ricardo Ferreira Nepomuceno

Rua Maquipó, 23

VL Solange Guaianases, São Paulo

CEP 08410-350

\section{Agradecimentos}

Para o CNPq e Universidade de Mogi das Cruzes pela bolsa de Iniciação Científica. 